\title{
Monoamine reuptake inhibition and mood-enhancing potential of a specified oregano extract
}

\author{
Annis O. Mechan ${ }^{1 *}$, Ann Fowler ${ }^{1}$, Nicole Seifert ${ }^{1}$, Henry Rieger ${ }^{1}$, Tina Wöhrle ${ }^{1}$, Stéphane Etheve ${ }^{1}$, \\ Adrian Wyss ${ }^{1}$, Göde Schüler ${ }^{1}$, Biagio Colletto ${ }^{1}$, Claus Kilpert ${ }^{1}$, James Aston ${ }^{2}$, J. Martin Elliott ${ }^{2}$, \\ Regina Goralczyk ${ }^{1}$ and M. Hasan Mohajeri ${ }^{1}$ \\ ${ }^{1}$ DSM Nutritional Products Limited, Research and Development Human Nutrition and Health, PO Box 2676, \\ CH-40O2 Basel, Switzerland \\ ${ }^{2}$ Leicester School of Pharmacy, De Montfort University, The Gateway, Leicester LE1 9BH, UK
}

(Received 12 April 2010 - Revised 9 October 2010-Accepted 1 November 2010 - First published online 21 December 2010)

\section{Abstract}

A healthy, balanced diet is essential for both physical and mental well-being. Such a diet must include an adequate intake of micronutrients, essential fatty acids, amino acids and antioxidants. The monoamine neurotransmitters, serotonin, dopamine and noradrenaline, are derived from dietary amino acids and are involved in the modulation of mood, anxiety, cognition, sleep regulation and appetite. The capacity of nutritional interventions to elevate brain monoamine concentrations and, as a consequence, with the potential for mood enhancement, has not been extensively evaluated. The present study investigated an extract from oregano leaves, with a specified range of active constituents, identified via an unbiased, high-throughput screening programme. The oregano extract was demonstrated to inhibit the reuptake and degradation of the monoamine neurotransmitters in a dose-dependent manner, and microdialysis experiments in rats revealed an elevation of extracellular serotonin levels in the brain. Furthermore, following administration of oregano extract, behavioural responses were observed in mice that parallel the beneficial effects exhibited by monoamine-enhancing compounds when used in human subjects. In conclusion, these data show that an extract prepared from leaves of oregano, a major constituent of the Mediterranean diet, is brain-active, with moderate triple reuptake inhibitory activity, and exhibits positive behavioural effects in animal models. We postulate that such an extract may be effective in enhancing mental well-being in humans.

Key words: Oregano extract: Monoamine reuptake inhibition: Mood-enhancing potential: In vivo microdialysis

A healthy, balanced diet, including an adequate intake of micronutrients, essential fatty acids, amino acids and antioxidants, is essential for both physical and mental well-being. Nutrients which are particularly important for brain development and function include $n$-3 PUFA, minerals such as $\mathrm{Zn}, \mathrm{Mg}$ and $\mathrm{Fe}$, and vitamins such as folate, $B$ vitamins and vitamins $C$ and $E^{(1-3)}$. The monoamine neurotransmitters, serotonin, dopamine and noradrenaline (NA), are synthesised from dietary amino acids; specifically, serotonin is synthesised from the essential amino acid, tryptophan, and dopamine and NA are synthesised from tyrosine. The rate of synthesis of these neurotransmitters is therefore sensitive to the supply of their respective precursors ${ }^{(4,5)}$. Following their synthesis, serotonin, dopamine and NA are released into the synaptic cleft to act at post-synaptic receptor sites. Neurotransmitter action is terminated by reuptake into the pre-synaptic neuron through the activity of high-affinity $\mathrm{Na}^{+} / \mathrm{Cl}^{-}$-dependent serotonin, dopamine and NA reuptake transporters (SERT, DAT and NAT, respectively) and enzymatic degradation by monoamine oxidase (MAO; all three neurotransmitters) or catechol-O-methyltransferase (dopamine and NA) ${ }^{(5-7)}$. Activity of the monoamine neurotransmitters can thus be enhanced by inhibition of MAO and/or by inhibition of the reuptake transporters.

Together, the activity of these three neurotransmitters plays an essential role in many of man's basic physiological and behavioural functions. In particular, serotonin (5-hydroxytryptamine (5-HT)) is implicated in cardiovascular regulation, respiration and thermoregulation, as

Abbreviations: 5-HIAA, 5-hydroxyindoleacetic acid; 5-HT, 5-hydroxytryptamine; ASP, 4-(4-(dimethylamino)-styryl)- $N$-methylpyridinium; CAR, carvacrol; CLO, clobazam; DMSO, dimethylsulphoxide; FLU, fluoxetine; hDAT, human dopamine transporter; hNAT, human noradrenaline transporter; hSERT, human serotonin transporter; $\mathrm{IC}_{50}$, half maximal inhibitory concentration; IMI, imipramine; i.p., intraperitoneal; MAO, monoamine oxidase; NA, noradrenaline; p.o., per os; TQ, thymoquinone; VEH, vehicle; VEN, venlafaxine. 
well as in circadian rhythm entrainment, the sleep-wake cycle, appetite, mood, aggression, sexual behaviour, sensorimotor reactivity, pain sensitivity and learning ${ }^{(8)}$; dopamine is involved in locomotor activity, cognition, emotion, positive reinforcement, food intake and endocrine regulation $^{(9)}$; NA is involved in mediating attention, anxiety, arousal, food intake and learning and memory ${ }^{(6)}$. Dysregulation of the monoaminergic neurotransmitter pathways is therefore implicated in alterations in mood, appetite, sleep and activity, and sexual and cognitive dysfunction $^{(8)}$.

Nutritional components have been demonstrated to modulate mood and cognitive performance in healthy individuals. For example, 12 weeks' supplementation with a multi-vitamin/mineral composition in healthy children resulted in improved attention, but was associated with decrements in recognition memory ${ }^{(10)}$. Several randomised, placebo-controlled, double-blind, balanced, crossover studies have been performed using a computerised test battery: in healthy young adults, Melissa officinalis (lemon balm) improved attention and increased 'calmness', but reduced alertness and disrupted memory performance ${ }^{(11)}$; Salvia lavandulaefolia (Spanish sage) essential oil improved different aspects of $\operatorname{mood}^{(12)}$ and memory ${ }^{(12,13)}$ in healthy young adults; Salvia officinalis improved cognitive function in healthy older individuals and has been demonstrated to have significant anticholinesterase inhibition effects ${ }^{(14)}$.

It is likely that the mechanisms of action of vitamins/minerals and plant extracts, with the ability to modulate mood and cognition, are diverse and involve several neurotransmitter systems. To this end, in vitro and in vivo activity of specific compounds or plant extracts provides important information concerning putative mechanisms of action and indications for mood and cognition enhancement in human subjects. For example, constituents of liquorice significantly inhibited radiolabelled serotonin $\left(\left[{ }^{3} \mathrm{H}\right]-5-\mathrm{HT}\right)$ reuptake ${ }^{(15)}$, and cis- and trans-resveratrol concentrationdependently inhibited $\left[{ }^{3} \mathrm{H}\right]-5-\mathrm{HT}$ and radiolabelled NA $\left(\left[{ }^{3} \mathrm{H}\right]-\mathrm{NA}\right)$ uptake, in addition to inhibiting the activity of $\mathrm{MAO}^{(16)}$. These in vitro data indicate potential antidepressant-like effects through the enhancement of serotonergic $^{(15,16)}$ or noradrenergic ${ }^{(16)}$ neurotransmission. Moreover, animal data provide evidence that natural products, such as liquorice extract ${ }^{(17,18)}$ or essential oils from Citrus aurantium L. ${ }^{(19)}$, may have antidepressant-like activity ${ }^{(17)}$, improve cognition $^{(18)}$ or have anxiolytic potential ${ }^{(19)}$, and the observed antidepressant-like effects of liquorice extract may be mediated via NA and dopamine ${ }^{(17)}$.

A recent empirical study comprised assessment of the attitudes of both the general public and general practitioners, with respect to the use of pharmaceuticals and natural remedies by healthy people, to improve concentration, mood and memory. The results indicated that enhancement by means of natural remedies was more acceptable to the general public than the use of pharmaceuticals for the same purpose ${ }^{(20)}$. Thus, the use of plant-derived compounds or plant extracts to improve mood and cognition in healthy individuals is of general interest, yet has not been systematically investigated to date.

In the present study, we subjected a library of several thousand pure phytochemicals and plant extracts to a high-throughput, non-radioactive human SERT (hSERT) functional screening assay, whereby test compounds' ability to inhibit the uptake of a fluorescent substrate was measured $^{(21)}$. We identified a two-step, supercritical fluid $\mathrm{CO}_{2}$ oregano extract, with a specified range of active constituents, as having strong inhibitory activity. Furthermore, the oregano extract was demonstrated to inhibit the reuptake of radiolabelled serotonin, NA and dopamine, as well as inhibiting MAO-A enzymatic activity. In vivo microdialysis data further confirmed serotonergic activity of oregano extract, and results of the forced swim test and the marble-burying test parallel those reported for antidepressant-like and anxiolytic-like compounds, respectively. Finally, carvacrol (CAR), the main constituent of oregano extract, was measurable in dose-dependent levels in mouse plasma and brain tissue following a subchronic dosing schedule.

\section{Materials and methods}

\section{Preparation of oregano extract (oréVida ${ }^{\mathrm{TM}}$ )}

Extracts were prepared by Flavex (FLAVEX Naturextrakte $\mathrm{GmbH}$, Rehlingen, Germany). In brief, dried leaves of oregano were mechanically milled and extracted with $\mathrm{CO}_{2}$ under supercritical conditions (100 bar, $45^{\circ} \mathrm{C}, 1 \mathrm{~kg} \mathrm{CO} / \mathrm{kg}$ of plant material). The lipophilic components dissolved by this process were transferred to a second vessel (separator), and the final extract was obtained by reducing pressure to 60 bar at $30^{\circ} \mathrm{C}$. Analysis of a typical oregano extract produced by this process, using $\mathrm{GC} / \mathrm{MS}$, revealed a total content of essential oils of up to $89 \%$. The principal volatile components, included within oregano extracts used in the studies described below, were identified as terpinene (0.2\%), thymol $(0 \cdot 2-0 \cdot 4 \%)$, 4-terpineol $(0 \cdot 3-1 \cdot 5 \%)$, caryophyllene $(1 \cdot 5-1 \cdot 9 \%), p$-cymene $(2 \cdot 4-7 \cdot 8 \%)$, thymoquinone (TQ; 4-23.2\%) and CAR (50-79.9\%). The exception was the spike assay, where an extract including 0.1 and $0.6 \%$ of TQ and CAR, respectively, was used (see below).

\section{In vitro determination of mechanisms of action of oregano extract}

Cell culture. HEK-293 cells stably expressing the hSERT were obtained from R. Blakely (Vanderbilt School of Medicine, Nashville, TN, USA) ${ }^{(22)}$. The cells were routinely grown in poly-L-lysine-pretreated dishes in Dulbecco's modified Eagle's medium (Bioconcept, Allschwil, Switzerland), containing 10\% dialysed fetal calf serum, penicillin, streptomycin, L-glutamine and the antibiotic G418 
(Invitrogen, Paisley, UK), and passaged by trypsinisation before cell confluence occurred.

Non-radioactive high-throughput screening assay. This assay has been described in detail elsewhere ${ }^{(21)}$. Briefly, hSERT-expressing HEK-293 cells from 80\% confluent flasks were harvested $48 \mathrm{~h}$ before assay and seeded (75000 cells/well) into poly-D-lysine-coated ninetysix-well plates (Becton Dickinson, Bedford, MA, USA). Immediately before assay, the medium was exchanged for Krebs-Ringer-HEPES buffer (130 mM-NaCl, 1.3 mM-KCl, $2.2 \mathrm{~mm}^{-\mathrm{CaCl}_{2}}, \quad 1.2 \mathrm{~mm}_{-} \mathrm{MgSO}_{4}, \quad 1.2 \mathrm{~mm}-\mathrm{KH}_{2} \mathrm{PO}_{4}$ and $10 \mathrm{~mm}-$ HEPES, pH 7.3) supplemented with glucose ( $1.8 \mathrm{~g} / 1)$, ascorbic acid $(100 \mu \mathrm{M})$ and pargyline $(100 \mu \mathrm{M})$. The fluorescent substrate 4-(4-(dimethylamino)-styryl)- $N$-methylpyridinium (ASP; Sigma-Aldrich, St Louis, MO, USA) was added (final concentration $1 \mu \mathrm{M}$ ) and incubated at $37^{\circ} \mathrm{C}, 5 \% \mathrm{CO}_{2}, 95 \%$ humidity for $60 \mathrm{~min}$. Unincorporated ASP was removed by washing three times with $300 \mu \mathrm{l}$ Krebs-Ringer-HEPES containing $1 \mathrm{~mm}$-imipramine (IMI), and the cells were lysed by the addition of SDS ( $1 \%$ final concentration). The incorporated ASP was quantified by fluorescence intensity $\left(\lambda_{\mathrm{ex}}=485 \mathrm{~nm}\right.$ and $\lambda_{\mathrm{em}}=620 \mathrm{~nm}$ ) using an Analyst System (Molecular Devices Corporation, Sunnyvale, CA, USA). The assay was automated using the CyBio CyBi Well for compound addition, the Labsystems Multidrop for ASP addition and the Titertek MAP-C system for plate washing. The effect of oregano extract on the transporter function was determined by its inclusion in the assay at a concentration of $25 \mu \mathrm{g} / \mathrm{ml}$ for $10 \mathrm{~min}$ before and during incubation with ASP.

Radiolabelled serotonin uptake assay. On the day of assay, hSERT-expressing HEK-293 cells from $80 \%$ confluent flasks were harvested by gentle washing with warm $\left(37^{\circ} \mathrm{C}\right)$ PBS. Cells were then washed once by centrifugation, resuspended in Krebs-Ringer bicarbonate buffer (SigmaAldrich), supplemented with $100 \mu \mathrm{M}$-pargyline, $2.2 \mathrm{~mm}$ $\mathrm{CaCl}_{2}, 100 \mu \mathrm{m}$-ascorbic acid and $10 \mathrm{~mm}$-HEPES (pH 7.3), and aliquoted into round-bottomed, polypropylene, ninety-six-well microtitre plates (Nunc, Roskilde, Denmark) at a density of 10000 cells/well. Serotonin uptake into the cells was determined by the addition of radiolabelled serotonin ( $\left[{ }^{3} \mathrm{H}\right]-5-\mathrm{HT}$; Amersham, Buckinghamshire, UK) at a concentration of $20 \mathrm{~nm}$, and incubation for $40 \mathrm{~min}$ at $37^{\circ} \mathrm{C}$ with gentle shaking. Subsequently, unincorporated $\left[{ }^{3} \mathrm{H}\right]-5$ HT was removed by filtration through Unifilter 96 GF/B plates (Perkin Elmer, Wellesley, MA, USA) using a Tomtec Mach III M cell harvester. The incorporated $\left[{ }^{3} \mathrm{H}\right]-5-\mathrm{HT}$ retained on the plates was quantified by liquid scintillation counting using Microscint-40 and measured using a Topcount (Perkin Elmer) with quench correction. The effects of oregano extract on the transporter function were determined by its inclusion in the assay at a range of concentrations $(0.03-100 \mu \mathrm{g} / \mathrm{ml})$ for $10 \mathrm{~min}$ before and during incubation with radiolabelled serotonin.

Radiolabelled noradrenaline and dopamine uptake assays. Measurements of NA and dopamine reuptake inhibition by oregano extract were performed at MDS Pharma Taiwan (Taipei, Taiwan, ROC), according to the following methods. MDCK cells, stably expressing the human recombinant noradrenaline transporter (hNAT), or CHO$\mathrm{Ki} / \mathrm{hDAT}$ cells expressing the human dopamine transporter (hDAT) were plated $24 \mathrm{~h}$ before the assay. The cells $\left(2 \times 10^{5} / \mathrm{ml}\right)$ were preincubated with the oregano extract (ten concentrations; $3 \mathrm{ng} / \mathrm{ml}-100 \mu \mathrm{g} / \mathrm{ml}$ ) or vehicle in modified Tris-HEPES buffer $(\mathrm{pH} 7 \cdot 1)$ at $25^{\circ} \mathrm{C}$ for $20 \mathrm{~min}$ before the addition of $25 \mathrm{~nm}$-radio-labelled NA ( $\left.\left[{ }^{3} \mathrm{H}\right]-\mathrm{NA}\right)$ or 50 nm-radio-labelled dopamine $\left(\left[{ }^{3} \mathrm{H}\right]-\mathrm{DA}\right)$, respectively, for $10 \mathrm{~min}$. Cells were then rinsed twice, and solubilised with $1 \%$ SDS lysis buffer, and the lysate was analysed to determine $\left[{ }^{3} \mathrm{H}\right]-\mathrm{NA}$ or $\left[{ }^{3} \mathrm{H}\right]-\mathrm{DA}$ uptake; specific signal was determined in the presence of $10 \mu \mathrm{m}$-desipramine or-nomifensine, respectively.

Monoamine oxidase assay. In order to determine the ability of oregano extract to act as an MAO inhibitor, the following assay was performed ${ }^{(23)}$. The organic amines p-tyramine and benzylamine were used as substrates for the MAO-A and MAO-B enzymes, respectively. The $\mathrm{H}_{2} \mathrm{O}_{2}$ produced by this reaction was quantified by reaction with vanillic acid and catalysed by horseradish peroxidase. The reactions were carried out in polystyrene microtitre plates. The MAO enzymes (final concentration $2 \mathrm{U} / \mathrm{ml}$; Sigma-Aldrich) were mixed with either $p$-tyramine or benzylamine (final concentration $0.5 \mathrm{~mm}$; Sigma-Aldrich), as appropriate, and the chromogenic solution (vanillic acid (Sigma-Aldrich), 4-aminoantipyrine (Sigma-Aldrich) and horseradish peroxidase (Sigma-Aldrich); final concentrations of $0.25,0.125 \mathrm{~mm}$ and $1 \mathrm{U} / \mathrm{ml}$, respectively) in $0 \cdot 2 \mathrm{M}$-potassium phosphate buffer ( $\mathrm{pH} 7 \cdot 6$ ). Following 40 min of incubation at $37^{\circ} \mathrm{C}$, absorbance was measured at $495 \mathrm{~nm}$ on a microtitre plate absorbance reader (Spectramax M5; Molecular Devices Corporation). The assay was performed in duplicate, and reference inhibitors such as clorgyline (for MAO-A) and pargyline (for MAO-B) were used as controls. In order to determine the maximum concentration of oregano extract, which could be tested in this assay, the effect of oregano extract on the horseradish peroxidase-catalysed portion of the reaction was independently determined by replacing the MAO enzyme with $\mathrm{H}_{2} \mathrm{O}_{2}$ (final concentration $0.2 \mathrm{~mm}$; Molecular Probes, Eugene, OR, USA). Thus, oregano extract was tested in the MAO assay up to the maximum concentration, which showed no interference in the horseradish peroxidase reaction or, in the case of no interference, a maximum concentration of $100 \mu \mathrm{g} / \mathrm{ml}$.

Determination of reversibility of monoamine oxidase inhibition. Dialysis was used to determine whether oregano extract acts as a reversible inhibitor or a deactivator of $\mathrm{MAO}^{(24)}$. Reversibility of MAO inhibition is important for the prevention of serious side effects associated with the first-generation, non-selective, irreversible MAO inhibitor antidepressants, caused by interactions with dietary tyramine ${ }^{(25)}$. MAO $(4 \mathrm{U} / \mathrm{ml})$ in the absence or the presence 
of oregano extract was preincubated in $0 \cdot 1 \mathrm{M}$-potassium phosphate buffer $(\mathrm{pH} 7.4)$ at $37^{\circ} \mathrm{C}$ for $15 \mathrm{~min}$. Subsequently, $0.5 \mathrm{ml}$ of the mixture was dialysed at $4^{\circ} \mathrm{C}$, with shaking, $v$. $40 \mathrm{ml}$ of outer buffer $(0 \cdot 1 \mathrm{M}$-potassium phosphate, $\mathrm{pH} 7 \cdot 4,5 \%$ sucrose). Spectra/Por dialysis tubing with a 6000-8000 molecular weight cut-off (Serva, Heidelberg, Germany) was used, and the outer buffer was replaced with fresh buffer after approximately 3, 18 and $21 \mathrm{~h}$. Non-dialysed aliquots of each mixture were maintained at $4^{\circ} \mathrm{C}$ over the same time period. In order to evaluate reversibility of the inhibition, MAO activity was measured as described above $24 \mathrm{~h}$ after the start of dialysis. The enzymatic activity in the dialysed mixture was compared with the corresponding non-dialysed aliquot and expressed as a percentage of control.

Oregano extract and carvacrol/thymoquinone spike assay. In order to determine whether two of the main components of oregano extract, TQ and CAR, were responsible for the hSERT inhibitory effects of the extract, the following assay was performed. An oregano extract containing very low levels of TQ $(0 \cdot 1 \% ; 0.244 \mu \mathrm{M})$ and CAR $(0.6 \% ; 1.6 \mu \mathrm{M})$ was chosen for the assay. Exogenous TQ or CAR (at a range of concentrations from 1 to $100 \mu \mathrm{M}$; Sigma-Aldrich) was added to the half maximal inhibitory concentration $\left(\mathrm{IC}_{50}\right)$ of oregano extract $(40 \mu \mathrm{g} / \mathrm{ml})$, and radiolabelled serotonin uptake assays were performed as described above.

\section{In vivo efficacy of oregano extracts}

Animals and husbandry. At Porsolt \& Partners Pharmacology (Le Genest-St-Isle, France), male Rj:NMRI mice (5-6 weeks of age; Elevage Janvier, Le Genest-St-Isle, France) were used for acute testing of oregano extract. Mice were housed in groups of ten and, at the start of the experimental phase, were randomly assigned to test groups ( $n$ 15). Each individual mouse was only tested in one of the three behavioural paradigms.

In-house, male Balb/c mice (5-6 weeks of age; RCC, Füllinsdorf, Switzerland) were used for sub-chronic testing of oregano extract. Mice were housed in groups of three and were randomly assigned to test groups ( $n$ 10) at the start of the experimental phase. These mice were selected based on the evidence that they demonstrate higher baseline immobility and lower overall variability than several outbred strains $^{(26)}$ and enabled verification of the behavioural effects of oregano extract in a second mouse strain.

For the in vivo microdialysis study (Leicester School of Pharmacy, De Montfort University, Leicester, UK), male Sprague-Dawley rats (250-320 g; Harlan UK Limited, Bicester, UK) were housed in groups of four to five.

In all cases, animals were housed under conditions of controlled temperature and humidity and a $12 \mathrm{~h}$ light$12 \mathrm{~h}$ dark cycle, with free access to food and water. Mice and rats were acclimatised to the respective testing facility for a minimum of $5 \mathrm{~d}$ before commencement of testing.
All animal studies were performed under appropriate personal and institutional licenses and in accordance with the relevant national and international animal protection legislation.

Test compounds and compound administration. For intraperitoneal (i.p.) administration, oregano extract (FLAVEX) was prepared in a suspension with 3\% dimethylsulphoxide (DMSO; Coopération Pharmaceutique Française, Melun Cédex, France) and 3\% Tween 80 (Sigma-Aldrich) in physiological saline (0.9\% NaCl; Laboratoire Aguettant, Lyon, France); for per os (p.o.) administration, oregano extract was diluted in tocopherol-stripped corn oil (Dyets, Inc., Bethlehem, PA, USA). In behavioural studies, the reference compounds, fluoxetine (FLU; Merck, Darmstadt, Germany or Sigma-Aldrich), clobazam (CLO; SanofiSynthélabo, Paris, France) and venlafaxine (VEN; Merck), were dispersed in $0 \cdot 2 \%$ hydroxypropylmethylcellulose (Sigma-Aldrich); the reference compound imipramine hydrochloride (IMI; Sigma-Aldrich) was dissolved in saline; vehicle-treated (VEH) control mice were administered either 3\% DMSO/3\% Tween 80 in saline (i.p.) or corn oil (p.o.). In the rat microdialysis studies, oregano extract was prepared in 3\% DMSO/3\% Tween 80 in saline, and the reference compounds, FLU and IMI, were dissolved in saline.

In all acute behavioural studies, test compounds and vehicle were administered i.p., in a volume of $10 \mathrm{ml} / \mathrm{kg}$, 30 min before commencement of the behavioural tests. In studies where sub-chronic treatment was employed, mice were administered test compounds or vehicle $(10 \mathrm{ml} / \mathrm{kg}$, p.o.) 24,5 and $1 \mathrm{~h}$ before the start of the test, unless otherwise stated. In the rat microdialysis study, test compounds or vehicle were administered i.p., in a volume of $1 \mathrm{ml} / \mathrm{kg}$, at 0,60 and $120 \mathrm{~min}$. Doses of oregano extract and reference compounds employed for the different behavioural and microdialysis studies are detailed below.

\section{Behavioural tests}

Forced swim test. The forced swim (behavioural despair) test was developed to determine the potential antidepressant activity of pharmaceutical compounds, whereby effective compounds reduce the immobility behaviour of mice forced to swim in a narrow cylinder ${ }^{(27)}$. At Porsolt \& Partners Pharmacology, the test was performed in the following manner: mice were individually placed in a clear perspex cylinder containing water $\left(22^{\circ} \mathrm{C}\right)$, from which they could not escape, and were observed for swimming and immobility behaviour, which was measured using a stopwatch and recorded in a score sheet. The test lasted for $6 \mathrm{~min}$, and the duration of immobility during the last $4 \mathrm{~min}$ of the test was subsequently analysed ${ }^{(27)}$. Oregano extract was tested at doses of 10,30 and $60 \mathrm{mg} / \mathrm{kg}$, i.p.; IMI $(32 \mathrm{mg} / \mathrm{kg}$, i.p.; tricyclic antidepressant with strong serotonin and NA reuptake inhibition activity) and VEN (16 mg/kg, i.p.; serotonin/NA reuptake inhibitor) were used as the reference compounds. 
In-house, the forced swim test was performed using an automated recording system as follows. Mice were individually placed in a polypropylene cylinder containing water $\left(22 \pm 1^{\circ} \mathrm{C}\right)$, from which they could not escape. Experiments were monitored via a black and white CCD camera mounted above the swim test arena, and duration of immobility and swimming behaviour was automatically recorded via VideoMot2 software (TSE Systems GmbH, Bad Homburg, Germany). The test lasted for $6 \mathrm{~min}$, and the duration of immobility during the last $4 \mathrm{~min}$ of the test was subsequently analysed. Oregano extract was tested at doses of 75,150 and $300 \mathrm{mg} / \mathrm{kg}$, p.O.; IMI (32 mg/kg, p.o.) was used as the reference compound.

Marble-burying test. The marble-burying test, developed to measure anxiolytic ${ }^{(28,29)}$ or obsessive-compulsive ${ }^{(30)}$ behaviour, was performed as described by Broekkamp et al. ${ }^{(31)}$. Briefly, mice were individually tested in a transparent plastic cage $(33 \times 21 \times 18 \mathrm{~cm})$, containing $5 \mathrm{~cm}$ sawdust spread evenly across its base. A total of twenty-five marbles $(1 \mathrm{~cm}$ in diameter) were grouped in the centre of the cage, and the number of marbles, which were (at least two-thirds) covered with sawdust, was counted at the end of a 30 min test period. Oregano extract was tested at doses of 10,30 and $60 \mathrm{mg} / \mathrm{kg}$, i.p.; FLU (32 mg/kg, i.p.; selective serotonin reuptake inhibitor) and VEN (16 mg/kg, i.p.) were used as the reference compounds. In order to ensure that marbles were not buried purely due to possessing an unfamiliar odour, each test cage and set of marbles were subjected to a $15 \mathrm{~min}$ period during which ten naive mice were left to explore the cage, thus 'impregnating' the test arena with a typical mouse odour.

Light-dark box test. The light-dark box test, which is used to detect the potential anxiolytic activity of compounds, was performed as described by Crawley ${ }^{(32)}$. Briefly, the light-dark box comprised a light, open compartment $(25 \mathrm{~cm}$ (height) $\times 27 \mathrm{~cm} \quad$ (width) $\times 27 \mathrm{~cm} \quad$ (length) $)$ and a dark, closed compartment $(20 \mathrm{~cm}$ (height $) \times 27 \mathrm{~cm}$ (width) $\times 27 \mathrm{~cm}$ (length)). At the start of a 3 min test, each mouse was placed in the light compartment, and the time spent in the light compartment was recorded. Oregano extract was tested at doses of 10,30 and $60 \mathrm{mg} / \mathrm{kg}$, i.p.; CLO (16 mg/kg, i.p.; benzodiazepine with anxiolytic activity) and $\operatorname{VEN}(16 \mathrm{mg} / \mathrm{kg}$, i.p.) were used as the reference compounds.

\section{In vivo microdialysis in the rat hippocampus}

In order to assess the ability of oregano extract to increase extracellular monoamine levels in living brain tissue, in vivo microdialysis was performed in rats. Previous studies using potent inhibitors of monoamine transporters, such as FLU and IMI, have been shown to induce a significant increase in extracellular serotonin levels following acute administration in anaesthetised ${ }^{(33,34)}$ and freelymoving $^{(35-37)}$ rats.
Implantation of microdialysis probes. Rats were anaesthetised using chloral hydrate ( $400 \mathrm{mg} / \mathrm{kg}$, i.p.), and a single microdialysis probe (BASi type MD2200, $2 \mathrm{~mm}$ membrane, 30000 Dalton cut-off; BASi, Kenilworth, UK) was implanted in the dorsal hippocampus, using a stereotaxic frame, at the following coordinates: rostrocaudal $-4.5 \mathrm{~mm}$, mediolateral $-2.5 \mathrm{~mm}$ and dorsoventral $-4.5 \mathrm{~mm}$ from the bregma and dural surface ${ }^{(38)}$, and fixed in position using dental cement. Body temperature was maintained at $36^{\circ} \mathrm{C}$ using a heating pad and monitored via a digital rectal thermometer. The microdialysis probe was perfused with artificial cerebrospinal fluid at $1 \mu \mathrm{l} / \mathrm{min}$, and perfusate samples were collected every $15 \mathrm{~min}$.

Treatment schedule. Preliminary studies demonstrated that, following implantation of the microdialysis probe, the 5-HT level was initially high due to release from platelets activated by blood clotting caused by the surgery. However, within $150 \mathrm{~min}$ of completion of the surgery, the basal 5-HT level was almost constant. Thus, injections of the test compound or vehicle were routinely administered 150, 210 and $270 \mathrm{~min}$ post-surgery (0, 60 and $120 \mathrm{~min}$ from the start of the test phase of the experiment), and perfusate samples were collected until $60 \mathrm{~min}$ following the final injection. Due to variability in basal 5-HT release between assays and variability in the efficiency of the microdialysis probes to detect 5-HT in the extracellular fluid, data were normalised according to the two values obtained immediately before the first injection (i.e. -15 and $0 \mathrm{~min}$ ), and data are expressed as percentage basal level (means with their standard errors).

Oregano extract was administered at doses of 10, 30 and $60 \mathrm{mg} / \mathrm{kg}$, i.p., and FLU and IMI (both administered at doses of 3, 10 and $30 \mathrm{mg} / \mathrm{kg}$, i.p.) were used as the reference compounds. The vehicle used for preparation of oregano extract was 3\% DMSO/3\% Tween 80 in saline, and the parallel VEH control group was administered $0 \cdot 2 \%$ hydroxypropylmethylcellulose. The reference compounds were compared with rats administered saline as vehicle. In initial studies, all three vehicles had been shown to have the same effects on 5-HT levels; thus, comparison of oregano extract (suspended in 3\% DMSO/3\% Tween 80 in saline) with $0.2 \%$ hydroxypropylmethylcellulose-treated control rats was deemed justified. On each day of testing, one oregano extract- or reference compound-treated rat was tested in parallel to one rat administered vehicle.

HPLC analysis of extracellular monoamine levels. Perfusate samples were assayed immediately for the determination of extracellular 5-HT and 5-hydroxyindoleacetic acid (5-HIAA) levels using HPLC with electrochemical detection. The HPLC mobile phase (0.5 mm-EDTA, $0.1 \mathrm{M}-$ monochloroacetic acid, $\mathrm{pH} 3 \cdot 1$, sodium octyl sulphate $(0 \cdot 15 \mathrm{~g} / 1), 5 \%$ acetonitrile and $0.7 \%$ tetrahydrofuran) was pumped through the system at $70 \mu \mathrm{l} / \mathrm{min}$, and monoamines were separated using a reverse-phase $1 \times 100 \mathrm{~mm}$ octadecyl silane (ODS) $3 \mu \mathrm{m}$ microbore column with a $5 \mu \mathrm{l}$ injection loop and detected using an Epsilon 
electrochemical detector (BASi) with a glassy carbon electrode set at $+650 \mathrm{mV} v$. an $\mathrm{Ag} / \mathrm{AgCl}$ reference electrode. Dialysate peaks were identified by comparing peak elution times with reference standards and quantified according to the measurement of peak area using linear regression analysis. The detection limits for 5-HT and 5-HIAA were defined as the sample amount producing a peak area twice that of the background noise per unit time and were both approximately $0 \cdot 1 \mathrm{fmol} /$ sample.

Following analysis of 5-HT and 5-HIAA levels, the remaining perfusate samples were stored at $-80^{\circ} \mathrm{C}$. Subsequently, samples were thawed on ice, and then assayed for the determination of extracellular NA content. The HPLC mobile phase (0.5 mm-EDTA, 0.1 M-NaH $\mathrm{PO}_{4}, \mathrm{pH}$ $3 \cdot 1,1 \mathrm{~mm}$-sodium octyl sulphate and $6 \%$ acetonitrile) was pumped through the system at $70 \mu \mathrm{l} / \mathrm{min}$, and monoamines were separated as described above. The detection limit for NA was approximately $0.3 \mathrm{fmol} / \mathrm{sample}$.

\section{Analysis of carvacrol levels in plasma and brain tissue of mice}

Sample collection. In order to determine the levels of $\mathrm{CAR}$, the principal component of oregano extract, in both plasma and brain tissue, mice were administered oregano extract $(25,75$ or $225 \mathrm{mg} / \mathrm{kg}$, p.o.) $24.5,18.5,5.5,3.5$ and $1.5 \mathrm{~h}$ before they were killed. Following cervical dislocation and opening of the abdominal and thoracic walls, blood samples were collected by cardiac puncture using a sterile syringe and immediately transferred into a polyethylene tube containing heparin. Samples were manually agitated and stored on ice until centrifugation $\left(4^{\circ} \mathrm{C}, 1500 \mathrm{~g}\right.$, $10 \mathrm{~min}$ ), which was performed within $30 \mathrm{~min}$ of sampling. Plasma was then immediately transferred to polypropylene tubes and stored at approximately $-70^{\circ} \mathrm{C}$ until analysis. After blood sampling, each mouse was decapitated and its brain was removed. Brains were rinsed in cold physiological saline; hemispheres were dissected on a refrigerated surface, snap frozen in liquid $\mathrm{N}_{2}$ and stored at approximately $-70^{\circ} \mathrm{C}$ until analysis.

Chemicals. CAR was obtained from Sigma-Aldrich. ${ }^{2} \mathrm{H}$-labelled thymol, used as an internal standard for CAR determination, was obtained from DSM Nutritional Products (Switzerland). Methanol and acetonitrile were of HPLC grade (Merck, Germany). All other chemicals and reagents were of analytical grade.

\section{Sample preparation}

Plasma. To determine total (aglycone + conjugated) CAR concentrations in plasma, $8 \mu$ l of the internal standard ( ${ }^{2} \mathrm{H}$-labelled thymol, $31.9 \mu \mathrm{g} / \mathrm{ml}$ ) was added to $25 \mu \mathrm{l}$ of freshly thawed plasma. Subsequently, digestion with $25 \mu \mathrm{l}$ $\beta$-glucuronidase enzyme $(2500 \mathrm{U} / \mathrm{ml})$ in ammonium acetate buffer (200 mm, pH 5) was performed, by incubating at $37^{\circ} \mathrm{C}$ for $24 \mathrm{~h}$, before deproteinisation with $100 \mu \mathrm{l}$ acetonitrile. After shaking horizontally for $10 \mathrm{~min}$, the samples were centrifuged $\left(15 \mathrm{~min}, 10^{\circ} \mathrm{C}\right)$, and the resulting supernatant was subjected to quantitative analysis via liquid chromatography with tandem MS (LC-MS/MS; see below).

Brain tissue. For quantification of CAR in brain tissue, approximately $200 \mathrm{mg}$ of brain tissue (one complete hemisphere, without cerebellum) was weighed exactly, and an equivalent weight of quartz sand (Büchi Labortechnik AG, Flawil, Switzerland) was added, followed by $1.5 \mathrm{ml}$ of the internal standard solution $\left({ }^{2} \mathrm{H}\right.$-labelled thymol, $335 \mathrm{ng} / \mathrm{ml}$ ). The mixture was vortexed, mechanically shaken for $20 \mathrm{~min}$, and then centrifuged ( $15 \mathrm{~min}$, approximately $7^{\circ} \mathrm{C}$ ). Of the resulting supernatant, $200 \mu \mathrm{l}$ was then diluted with $400 \mu \mathrm{l}$ of $0.05 \% \mathrm{NH}_{4} \mathrm{OH}$ solution, and the mixture was injected on to the LC-MS/MS system.

Apparatus. CAR levels in plasma and brain tissue were identified and quantified by LC-MS/MS analysis. LC analysis was performed using an Agilent series 1100 system (Agilent Technologies, Basel, Switzerland) equipped with a column switching system for online extraction. The purification column (Waters Xterra ${ }^{\mathrm{TM}} \mathrm{C} 18,2 \cdot 1 \mathrm{~mm} \times$ $10 \mathrm{~mm}, 3.5 \mu \mathrm{m}$ ) and analytical column (Waters Xterra ${ }^{\mathrm{rm}}$ C18, $3.0 \mathrm{~mm} \times 50 \mathrm{~mm}, 2.5 \mu \mathrm{m}$ ) were used at room temperature. Gradient elution for both columns was a mixture of $0.05 \% \mathrm{NH}_{4} \mathrm{OH}$ solution and acetonitrile. The volume of injection was $50 \mu \mathrm{l}$, and the autosampler was set to $10^{\circ} \mathrm{C}$. A triple quadrupole mass spectrometer (API Q TRAP4000; Applied Biosystems, Rotkreuz, Switzerland) equipped with a Heated Nebuliser (APCI) source in negative mode was used for the detection of compounds of interest. The criteria for identification and quantification were the retention time and multiple reaction monitoring transition, $149 \rightarrow 134$ for CAR and $151 \rightarrow 136$ for ${ }^{2} \mathrm{H}$-labelled thymol (internal standard).

Identification, calibration and quantification of carvacrol. The identification of CAR was carried out by comparing retention times with an authentic reference standard. Moreover, specific identifications were obtained by using multiple reaction monitoring signals of the LC-MS/MS system. Data acquisition of extracted ion chromatograms, integration and quantification was performed using Analyst ${ }^{\circledR}$ Software from Applied Biosystems, Inc. (Foster City, CA, USA). Quantification was performed by applying an external standard calibration curve covering the range of unknown samples. Additionally, quality of the analytical data was ensured by using quality-control samples. Calibration- and quality-control samples were analysed in the same manner as the unknown samples. The lower limit of quantification was set to $0.020 \mu \mathrm{g} / \mathrm{ml}$ for total CAR in the plasma, and to $0.025 \mu \mathrm{g} / \mathrm{g}$ for CAR in the brain.

\section{Statistics}

All data are shown as means with their standard errors, and significance levels of comparisons between means are all two-sided. The in vitro data are presented as the percentage of inhibition values, which were calculated relative 
to the fully inhibited controls from the same plate. Analysis of screening data was performed using $\mathrm{MDL}^{\circledR}$ Assay Explorer $^{\circledR} 2.2$ (Symyx Software, San Ramon, CA, USA), and curve fitting was performed using Origin 7 (OriginLab Corporation, Northampton, MA, USA).

Statistical analyses of all behavioural data and CAR data analyses were performed using SPSS (SPSS 17.0.1 ML R1; SPSS, Inc., Chicago, IL, USA). Inter-group comparisons were made using one-way ANOVA and, where appropriate, post hoc tests enabled pairwise comparisons; where homogeneity of variance occurred, a least significant difference post hoc test was used, where variances were non-homogeneous, Tamhane's $T 2$ test was used.

In vivo microdialysis data were analysed using GraphPad Prism (GraphPad Prism 3.0; GraphPad Software, Inc., La Jolla, CA, USA). Statistical comparison of the level of 5-HT or NA in the perfusate following administration of the test compound or vehicle was made by two-way ANOVA (test factors being treatment and time), followed by post hoc comparisons at individual time points using the Bonferroni $t$ test.

\section{Results}

In vitro inhibition of human serotonin, noradrenaline and dopamine transporters, and monoamine oxidase- $A$ and $-B$ enzymes

High-throughput screening of a library containing more than 32000 fractions, derived from 2400 pure phytochemicals and extracts of more than 500 edible plants, was performed. The primary screen comprised a non-radioactive, hSERT functional assay using hSERTexpressing HEK cells and identified a specific, supercritical fluid $\mathrm{CO}_{2}$ oregano extract as having strong (61\%) inhibitory activity. This result was confirmed in a subsequent assay using uptake of radiolabelled serotonin, where the oregano extract was shown to inhibit hSERT function in a reproducible and dose-dependent manner, with an $\mathrm{IC}_{50}$ of 3.2 (SEM 1.4$) \mu \mathrm{g} / \mathrm{ml}(n)$ ). Further profiling of the same extract against other relevant targets revealed a dosedependent inhibition of hNAT, hDAT and MAO-A and MAO-B, although the inhibition of MAO-B was considerably weaker than that of MAO-A. The inhibition of the MAO enzymes was fully reversible (data not shown). Representative dose-response curves for the effects of oregano extract on hSERT, hNAT, hDAT, MAO-A and MAO-B are shown in Fig. 1.

\section{Oregano extract and carvacrol/thymoquinone spike assay}

When increasing concentrations (1, 3.16, 10, 31.6 and $100 \mu \mathrm{M})$ of TQ or CAR were added to the $\mathrm{IC}_{50}$ concentration $(40 \mu \mathrm{g} / \mathrm{ml})$ of oregano extract (containing $0.244 \mu \mathrm{m}-\mathrm{TQ}+1.6 \mu \mathrm{m}$-CAR), percentage inhibition of hSERT was consistently increased above that of TQ or CAR alone (Table 1). These data thus indicate the importance of TQ and CAR in the serotonin reuptake inhibitory activity of oregano extract.

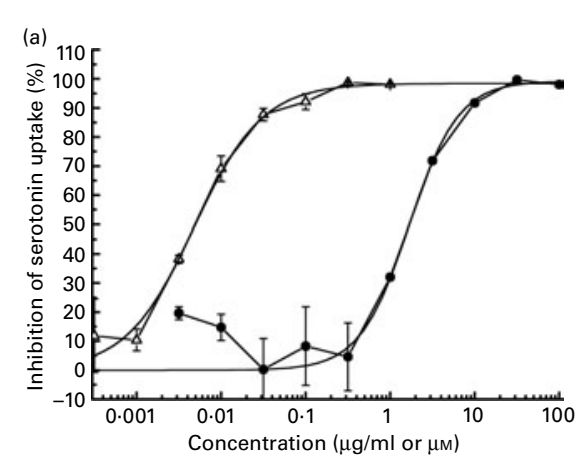

(d)

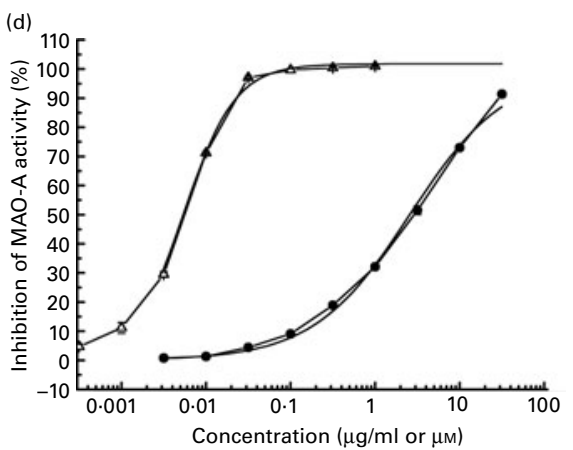

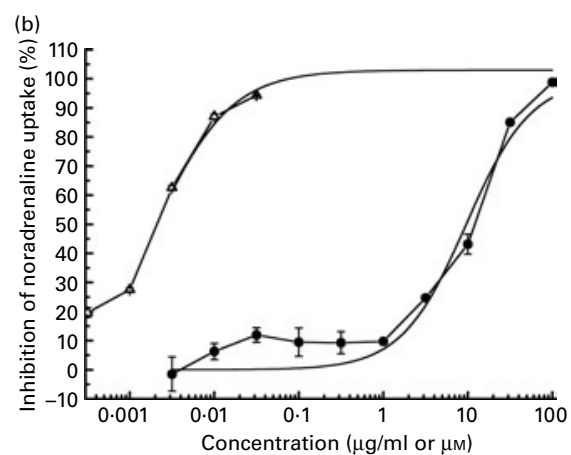
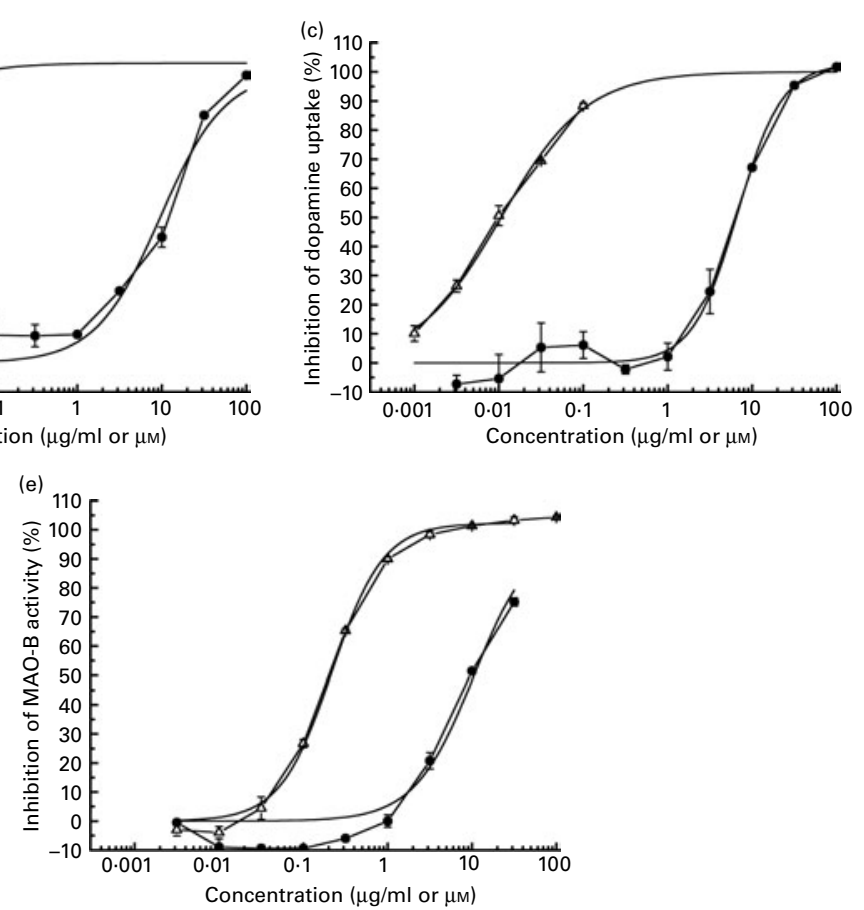

Fig. 1. Dose-dependent inhibition of (a) human serotonin, (b) human noradrenaline, (c) human dopamine transporters, (d) monoamine oxidase-A (MAO-A) and (e) monoamine oxidase-B (MAO-B) by oregano extract. Concentration refers to $\mu \mathrm{g} / \mathrm{ml}$ in the case of oregano extract $(-\bullet-$; half maximal inhibitory concentration $\left(I C_{50}\right)=$ (a) 1.7 , (b) 9.5 , (c) $6 \cdot 7$, (d) 2.6 and (e) $10.5 \mu \mathrm{g} / \mathrm{ml}$ ) and $\mu \mathrm{M}$ for the reference compounds $(-\Delta-)$ ((a) fluoxetine $\left(I C_{50}=4.8 \mathrm{~nm}\right)$, (b) desipramine $\left(I C_{50}=2.1 \mathrm{nM}\right)$, (c) nomifensine $\left(I C_{50}=10.6 \mathrm{nM}\right)$, (d) clorgyline $\left(I C_{50}=5.5 \mathrm{nM}\right)$ and $(\mathrm{e})$ Ro16-6491 $\left(\mathrm{IC}_{50}=216 \mathrm{nM}\right)$, respectively). Values are means, with standard errors represented by vertical bars (three wells). In each case, raw data are shown together with curves of best fit, enabling the calculation of $\mathrm{IC}_{50}$ values. 
Table 1. Thymoquinone (TQ) or carvacrol (CAR) $(1-100 \mu \mathrm{M})$ was added to oregano extract (OREG; half maximal inhibitory concentration $40 \mu \mathrm{g} / \mathrm{ml}$ ), which itself contained low levels of the two compounds $(0.1 \%(0.244 \mu \mathrm{M})$ and $0.6 \%(1.6 \mu \mathrm{M})$, respectively) $\dagger$

(Mean values with their standard errors, $n 4$ )

\begin{tabular}{|c|c|c|c|c|c|c|c|c|c|c|}
\hline \multirow{3}{*}{$\begin{array}{l}\text { TQ or CAR } \\
\text { concentration }(\mu \mathrm{M})\end{array}$} & \multicolumn{10}{|c|}{ Percentage inhibition of hSERT } \\
\hline & \multicolumn{2}{|c|}{$\mathrm{TQ}$} & \multicolumn{2}{|c|}{$\begin{array}{c}\text { OREG } \\
(40 \mu \mathrm{g} / \mathrm{ml})+\mathrm{TQ}\end{array}$} & \multirow{2}{*}{$\begin{array}{l}\text { Average increase } \\
\text { in inhibition (\%) }\end{array}$} & \multicolumn{2}{|c|}{ CAR } & \multicolumn{2}{|c|}{$\begin{array}{c}\text { OREG } \\
(40 \mu \mathrm{g} / \mathrm{ml})+\text { CAR }\end{array}$} & \multirow{2}{*}{$\begin{array}{c}\text { Average increase } \\
\text { in inhibition (\%) }\end{array}$} \\
\hline & Mean & SEM & Mean & SEM & & Mean & SEM & Mean & SEM & \\
\hline 1 & 30.41 & $8 \cdot 23$ & 58.09 & 2.96 & $+27 \cdot 68^{\star}$ & $12 \cdot 70$ & 2.04 & 51.68 & $5 \cdot 14$ & $+38.98^{\star \star \star}$ \\
\hline $3 \cdot 16$ & 27.54 & $1 \cdot 17$ & $58 \cdot 19$ & 0.91 & $+30.65^{\star * *}$ & $10 \cdot 54$ & $10 \cdot 21$ & 52.06 & 2.49 & $+41.52^{* *}$ \\
\hline 10 & $60 \cdot 76$ & 2.59 & $78 \cdot 71$ & $3 \cdot 22$ & $+17.95^{\star *}$ & 1.40 & 4.02 & 53.33 & $2 \cdot 21$ & $+51.93^{\star \star \star}$ \\
\hline $31 \cdot 6$ & 52.95 & $4 \cdot 30$ & $80 \cdot 77$ & 1.63 & $+27 \cdot 82^{\star \star \star}$ & 23.69 & 3.98 & 71.26 & 1.51 & $+47.57^{\star \star \star}$ \\
\hline 100 & 50.58 & 4.53 & $86 \cdot 26$ & 1.59 & $+35.68^{\star \star \star}$ & 24.57 & 2.23 & 78.74 & 0.70 & $+54 \cdot 17^{\star \star \star}$ \\
\hline
\end{tabular}

hSERT, human serotonin transporter.

Percentage inhibition values were significantly different (TQ alone $v$. OREG $+\mathrm{TQ}, \mathrm{CAR}$ alone $v$. OREG $+\mathrm{CAR}$ ): ${ }^{\star} P<0.05,{ }^{\star \star} P<0.01,{ }^{\star \star *} P<0.001$.

†Percentage inhibition of radiolabelled serotonin uptake for TQ and CAR alone and for OREG + TQ and OREG + CAR. The single compounds were marginally active, while their addition to oregano extract induced a consistent upward shift in the percentage inhibition curve compared with oregano extract alone.

\section{Effects of oregano extract in mouse behavioural tests}

Forced swim test. The activity of oregano extract in the forced swim test was assessed following both acute and sub-chronic administration. Acute treatment (oregano extract (OREG); 30 and $60 \mathrm{mg} / \mathrm{kg}$, i.p., $30 \mathrm{~min}$ before behavioural testing) resulted in a significant reduction in the duration of immobility, compared with VEH control mice, by 17 and $24 \%$, respectively (significant effect of group: $F(5,89)=26 \cdot 814, P<0 \cdot 001$; VEH $v$. OREG-30: $P=0.032$, VEH $v$. OREG-60: $P=0.003$; Fig. $2(\mathrm{a})$ ). The reduction in immobility was unlikely to be due to overall changes in locomotor activity, as neither stimulatory nor inhibitory effects of the extract were observed in a previous study comprising assessment of spontaneous locomotor activity in automated activity meters (Imetronic, Pessac, France; AO Mechan, unpublished results). The reference compounds, IMI $(32 \mathrm{mg} / \mathrm{kg})$ and VEN $(16 \mathrm{mg} / \mathrm{kg})$, significantly reduced the duration of immobility by 70 and $51 \%$, respectively $(P<0 \cdot 001)$. Sub-chronic, oral administration of oregano extract $(75,150$ and $300 \mathrm{mg} / \mathrm{kg}$, p.o., 24,5 and $1 \mathrm{~h}$ before testing) was effective in reducing the duration of immobility, compared with VEH mice, by 41 , 32 and $21 \%$, respectively. This activity reached statistical significance at the low and intermediate doses and was comparable with the effects of IMI $(32 \mathrm{mg} / \mathrm{kg}$ ) (significant effect of group: $F(4,49)=3.958, P=0.008$; VEH $v$. OREG-75: $P=0 \cdot 005$, VEH $v$. OREG-150: $P=0 \cdot 024$, VEH $v$. IMI: $P=0 \cdot 001$; Fig. 2(b)).

Marble-burying test. Anxiolytic effects of oregano extract $(10,30$ and $60 \mathrm{mg} / \mathrm{kg}$, i.p., administered $30 \mathrm{~min}$ before testing) were indicated by a reduction in the number of marbles buried (40, 73 and $67 \%$, respectively) compared with control mice (significant effect of group: $F(5,89)=14 \cdot 858, P<0 \cdot 001 ;$ VEH $v$. OREG-30 and VEH $v$. OREG-60: $P=0 \cdot 001$; Fig. 3). The observed effects were in agreement with the effects of the reference compounds, VEN $(16 \mathrm{mg} / \mathrm{kg}$, i.p., $-30 \mathrm{~min})$ and FLU $(32 \mathrm{mg} / \mathrm{kg}$, i.p., $-30 \mathrm{~min}$ ), which significantly reduced the number of marbles buried by 98 and $93 \%$, respectively $(P<0 \cdot 001)$.
Light-dark box test. To further explore the anxiolytic potential of oregano extract, mice were subjected to the light-dark box test. Oregano extract $(10$ and $60 \mathrm{mg} / \mathrm{kg}$, i.p., $30 \mathrm{~min}$ before testing) increased the time spent in the light compartment, compared with control mice, by 28 and $35 \%$, respectively, while the reference compound, CLO $(16 \mathrm{mg} / \mathrm{kg}$, i.p., $-30 \mathrm{~min})$, increased the time spent by $114 \%$ (significant effect of group: $F(5,89)=12 \cdot 723$, $P<0 \cdot 001$; VEH $v$. OREG-60: $P=0 \cdot 046$, VEH $v$. CLO: $P<0 \cdot 001$; Fig. 4).

\section{In vivo efficacy of oregano extract as a serotonin} transporter inhibitor

In vivo microdialysis studies in rats revealed that extracellular 5-HT levels in the hippocampus were slightly, but consistently, higher than in the VEH animals after each dose of oregano extract. Furthermore, additional transient increases after 30 and $60 \mathrm{mg} / \mathrm{kg}$ were observed (Fig. 5(a)). Analysis of 5-HT levels by two-way ANOVA over the entire period of investigation revealed a significant effect of treatment $(F(1,133)=11 \cdot 0, \quad P<0 \cdot 01)$ but no significant interaction effect of treatment $\times$ time $(F(13,133)=0.54$, $P>0 \cdot 05$ ). Timed comparison of 5-HT levels indicated no significant differences between oregano extract and vehicle at any specific time point, thus indicating continuously higher extracellular 5-HT levels in the brains of oregano extract-treated rats. Comparison of 5-HIAA levels showed no significant difference between oregano extract and vehicle (data not shown). The basal levels of 5-HT (5.77 (SEM 0.91) fmol/sample) and 5-HIAA (1102 (sЕм 53) fmol/ sample) in the oregano extract assays were not significantly different from the basal levels in the vehicle assays.

The reference compounds, both FLU and IMI, induced significant increases in extracellular 5-HT levels, as expected (Fig. 5(b)). FLU treatment resulted in an overall significant effect of treatment $(F(1,129)=192 \cdot 5, P<0 \cdot 001)$ and a significant interaction of treatment $\times$ time $(F(13,129)=9.942$, $P<0 \cdot 001)$, and significantly higher levels of extracellular 

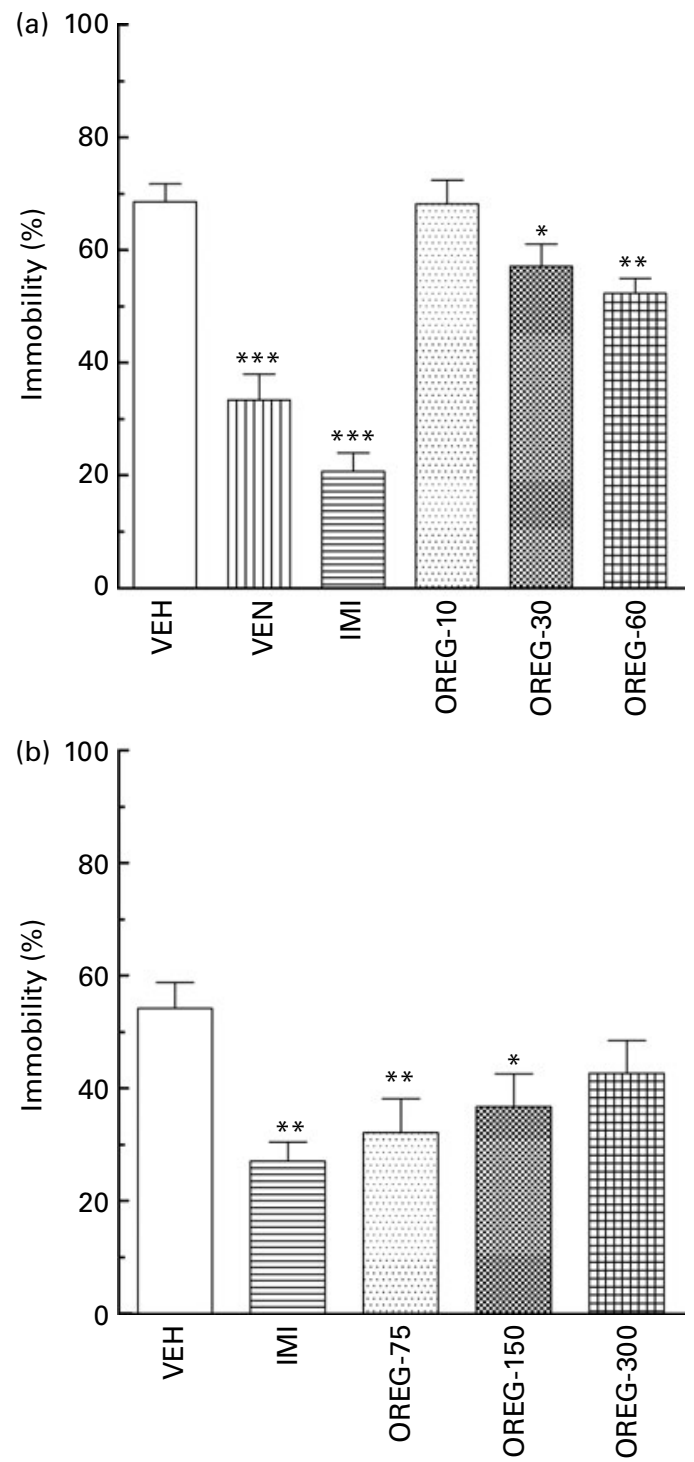

Fig. 2. Forced swim test. (a) Mice ( $n$ 15) were administered the test compound or vehicle, intraperitoneally, $30 \mathrm{~min}$ before the start of the test: vehicle (VEH; $3 \%$ dimethyl sulphoxide/3\% Tween 80 in saline), venlafaxine (VEN; $16 \mathrm{mg} / \mathrm{kg}$ ), imipramine (IMl; $32 \mathrm{mg} / \mathrm{kg}$ ) and oregano extract (OREG; 10,30 or $60 \mathrm{mg} / \mathrm{kg}$ ). (b) Mice ( $n$ 10) were administered the test compound or vehicle, per os, 24,5 and $1 \mathrm{~h}$ before the start of the test: VEH (maize oil), IMI $(32 \mathrm{mg} / \mathrm{kg})$ and OREG $(75,150$ or $300 \mathrm{mg} / \mathrm{kg})$. Duration of immobility, calculated as a percentage of total test time during the last $4 \mathrm{~min}$ of a $6 \mathrm{~min}$ test, is shown as means, with standard errors represented by vertical bars. Mean values were significantly different compared with the VEH control group: ${ }^{*} P<0.05, \quad{ }^{* \star} P<0.01, \quad{ }^{* \star} P<0.001$. OREG-30 and OREG-60 significantly reduced immobility behaviour, in agreement with the effects of both reference compounds. OREG-75 and OREG-150 significantly reduced immobility behaviour, in agreement with the effects of IMI.

5-HT were induced following the second dose of FLU $(P<0.05$ at all time points after $60 \mathrm{~min})$. In IMI-treated rats, a significant overall treatment effect was observed $(F(1,128)=37 \cdot 17, P<0 \cdot 001)$, but no interaction effect of treatment $\times$ time, while post hoc analysis revealed a significant difference between IMI- $(30 \mathrm{mg} / \mathrm{kg})$ and VEH rats at $150 \mathrm{~min}(P<0 \cdot 05)$. Comparison of 5-HIAA levels showed no significant effect of either FLU or IMI, compared with vehicle, at any time point (data not shown).
Following each administration of oregano extract (10, 30 and $60 \mathrm{mg} / \mathrm{kg}$, i.p.), the NA level increased and then returned to, or below, baseline before administration of the subsequent dose (Fig. 5(c)). However, comparison of NA levels by two-way ANOVA over the full period of investigation revealed no significant effect of treatment $(F(1,133)=11 \cdot 0, \quad P<0.60) \quad$ or interaction effect of treatment $\times$ time $(F(13,133)=1 \cdot 04, P>0.05)$. Timed comparison of NA levels indicated no significant differences between oregano extract and vehicle at any individual time point. The basal levels of NA (20.7 (SEM 4.1) fmol/sample) in the oregano extract assays were not significantly different from the basal levels in the vehicle assays.

The positive control compound, FLU, had no effect on NA levels (data not shown). NA levels were unaltered by the lowest dose of IMI, while $10 \mathrm{mg} / \mathrm{kg}$ induced a slight, but consistent, increase and, after administration of $30 \mathrm{mg} / \mathrm{kg}$, NA levels were significantly greater than observed in saline-treated control animals (Fig. 5(d)). Thus, a significant overall effect of treatment $(F(1,128)=90 \cdot 3, P<0 \cdot 001)$ and a significant interaction effect of treatment $\times$ time $(F(13,128)=5 \cdot 27, \quad P<0.001)$ were observed, in addition to significant increases at all time points after $120 \mathrm{~min}(P<0 \cdot 05)$.

\section{Analysis of carvacrol levels in mouse plasma and brain}

We have established an analytical method to quantify CAR, the principal component of oregano extract, in

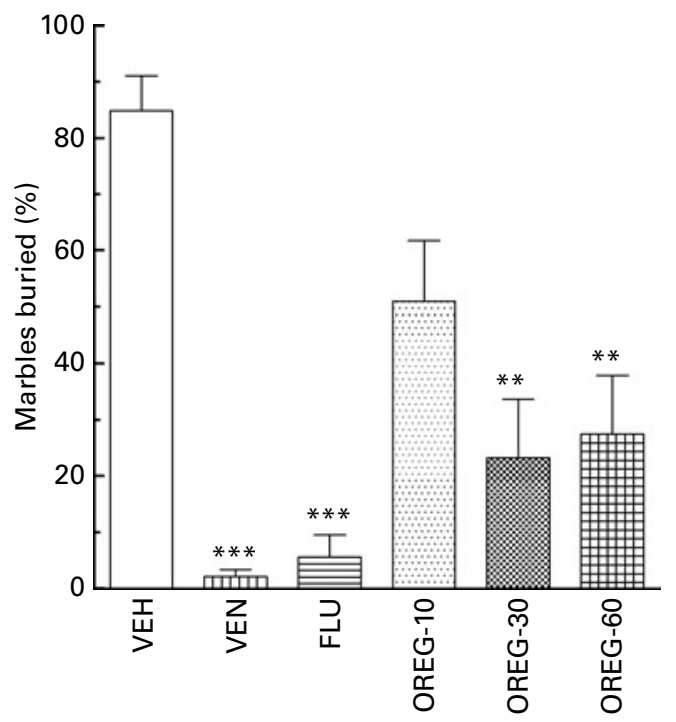

Fig. 3. Marble-burying test. Mice were administered the test compound or vehicle, intraperitoneally, $30 \mathrm{~min}$ before the start of the test: vehicle $(\mathrm{VEH}$; $3 \%$ dimethyl sulphoxide/3\% Tween 80 in saline), venlafaxine (VEN; $16 \mathrm{mg} / \mathrm{kg}$ ), fluoxetine (FLU; $32 \mathrm{mg} / \mathrm{kg}$ ) and oregano extract (OREG; 10,30 or $60 \mathrm{mg} / \mathrm{kg}$ ). The number of marbles buried during a $30 \mathrm{~min}$ test, calculated as a percentage of the total number of marbles present, is shown as means, with their standard errors represented by vertical bars ( $n$ 15). Mean values were significantly different compared with the vehicle control group: ${ }^{\star \star} P<0.01,{ }^{\star \star \star} P<0.001$. OREG-30 and OREG-60 significantly reduced marble-burying behaviour, in agreement with the effects of both reference compounds. 


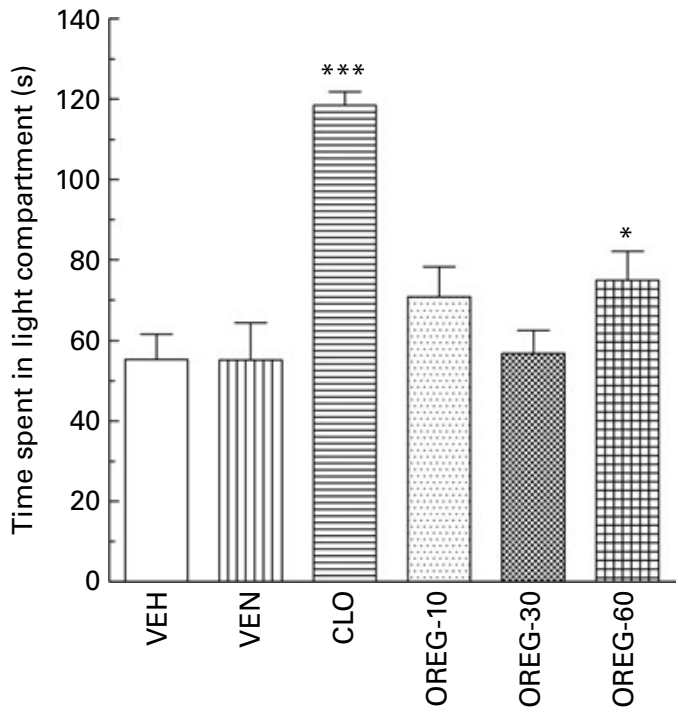

Fig. 4. Light-dark box test. Mice were administered the test compound or vehicle, intraperitoneally, $30 \mathrm{~min}$ before the start of the test: vehicle $(\mathrm{VEH}$; $3 \%$ dimethyl sulphoxide/3\% Tween 80 in saline), venlafaxine (VEN; $16 \mathrm{mg} / \mathrm{kg}$ ), clobazam (CLO; $16 \mathrm{mg} / \mathrm{kg}$ ) and oregano extract (OREG; 10, 30 or $60 \mathrm{mg} / \mathrm{kg}$ ). Time spent in the light compartment during a 3 min test is shown as means, with their standard errors represented by vertical bars ( $n$ 15). Mean values were significantly different compared with the vehicle control group: ${ }^{\star} P<0.05$, ${ }^{\star \star \star} P<0.001$. OREG-60 induced significant increases in time spent in the light compartment, in agreement with the effects of CLO.

mouse plasma and brain tissue following oral administration $(25,75$ and $225 \mathrm{mg} / \mathrm{kg}$, p.o., $24.5,18 \cdot 5,5.5,3.5$ and $1.5 \mathrm{~h}$ before tissue collection). Clear, dose-dependent CAR levels were observed in the plasma (significant effect of treatment: $F(3,39)=185 \cdot 146, P<0 \cdot 001$; post hoc comparisons of each treatment group with VEH: $P<0.001$; Fig. 6(a)). In brain tissue, CAR levels were below the limit of quantification $(<0.025 \mu \mathrm{g} / \mathrm{g})$ in all ten mice after administration of $25 \mathrm{mg} / \mathrm{kg}$, and in eight out of ten mice after administration of $75 \mathrm{mg} / \mathrm{kg}$. Nevertheless, 75 and $225 \mathrm{mg} / \mathrm{kg}$ resulted in CAR levels of 0.08 (SEM $0.03) \mu \mathrm{g} / \mathrm{g}$ and 0.19 (sem 0.09$) \mu \mathrm{g} / \mathrm{g}$, respectively (significant effect of treatment: $F(3,39)=3 \cdot 93, P=0 \cdot 016$; VEH $v$. OREG-225: $P=0 \cdot 007$; Fig. 6(b)).

\section{Discussion}

The results of the present study show that a supercritical fluid $\mathrm{CO}_{2}$ oregano extract, comprising a specified range of active constituents, acts as a moderate, natural, serotonin, NA and dopamine reuptake inhibitor, in addition to inhibiting monoamine catabolism in vitro. Subsequently, oregano extract was demonstrated to elevate brain extracellular serotonin levels in rats and to induce behavioural changes in mice characteristic of those generated by antidepressant- and anxiolytic-like compounds.

The monoamine neurotransmitters are involved in the mediation of a wide range of physiological and behavioural functions, including the sleep-wake cycle, appetite, mood, aggression ${ }^{(8)}$, locomotor activity, cognition, emotion $^{(9)}$, attention, anxiety, arousal, learning and memory $^{(6)}$. Therefore, dysregulation of one or more of the monoaminergic neurotransmitter pathways could result in alterations in mood, appetite, sleep and cognitive function. In clinical terms, treatment of mood disorders, including depression, is preferentially achieved through inhibition of one or more of the monoaminergic neurotransmitter reuptake transporters. In addition, extensive research during the past decade has led to the hypothesis that antidepressants with triple reuptake inhibitory activity may have a more rapid onset of effect and better efficacy over currently prescribed reuptake inhibitors of serotonin and/or NA, in part due to the addition of the dopamine component ${ }^{(39-42)}$.

The ultimate aim of the present study was not to identify a clinical antidepressant, but a plant-derived pure compound or plant extract with the potential for the enhancement of mood or mental well-being. To this end, we focused on increased synaptic activity of serotonin, NA and dopamine through inhibition of their reuptake. The results of the in vitro binding assays clearly showed that oregano extract had a triple reuptake inhibitor profile, exemplified by dose-dependent inhibition of the uptake of radioactively labelled serotonin, NA and dopamine. In addition, oregano extract dose dependently and reversibly inhibited the enzymatic activity of MAO-A. The reversibility of the inhibition is important for the prevention of side effects, such as hepatotoxicity, orthostatic hypotension and hypertensive crisis, as associated with the earlier MAO inhibitors ${ }^{(25)}$. The complementary effects of inhibiting both reuptake of the monoamine neurotransmitters and their enzymatic degradation provide the possibility of greater synaptic monoamine levels than would be the case for a compound which selectively inhibits either the uptake transporters or MAO, particularly following chronic dosing. It should be noted here that the $\mathrm{IC}_{50}$ values for uptake inhibition and enzymatic activity were approximately 1000 -fold lower than the $\mathrm{IC}_{50}$ values of the respective pharmacological reference compounds used in the present study. We postulate that such activity would be associated with the beneficial, mood-enhancing effects of triple reuptake inhibitors and MAO inhibitors while minimising the potential for side effects.

Microdialysis studies in rats demonstrated that oregano extract induced a small, but significant, increase in extracellular serotonin levels in the brain. Although considerably smaller than the effects of the tested reference compounds, FLU and IMI, this nevertheless indicates effective brain penetrance and neurochemical activity of oregano extract to increase synaptic levels of serotonin, most likely through inhibition of the serotonin transporter.

In order to assess the in vivo effects of oregano extract on behaviour, the optimal models were determined to be those where compounds with known monoamine reuptake inhibitory activity have proven efficacy ${ }^{(43-47)}$ Consequently, mice were subjected to the forced swim 

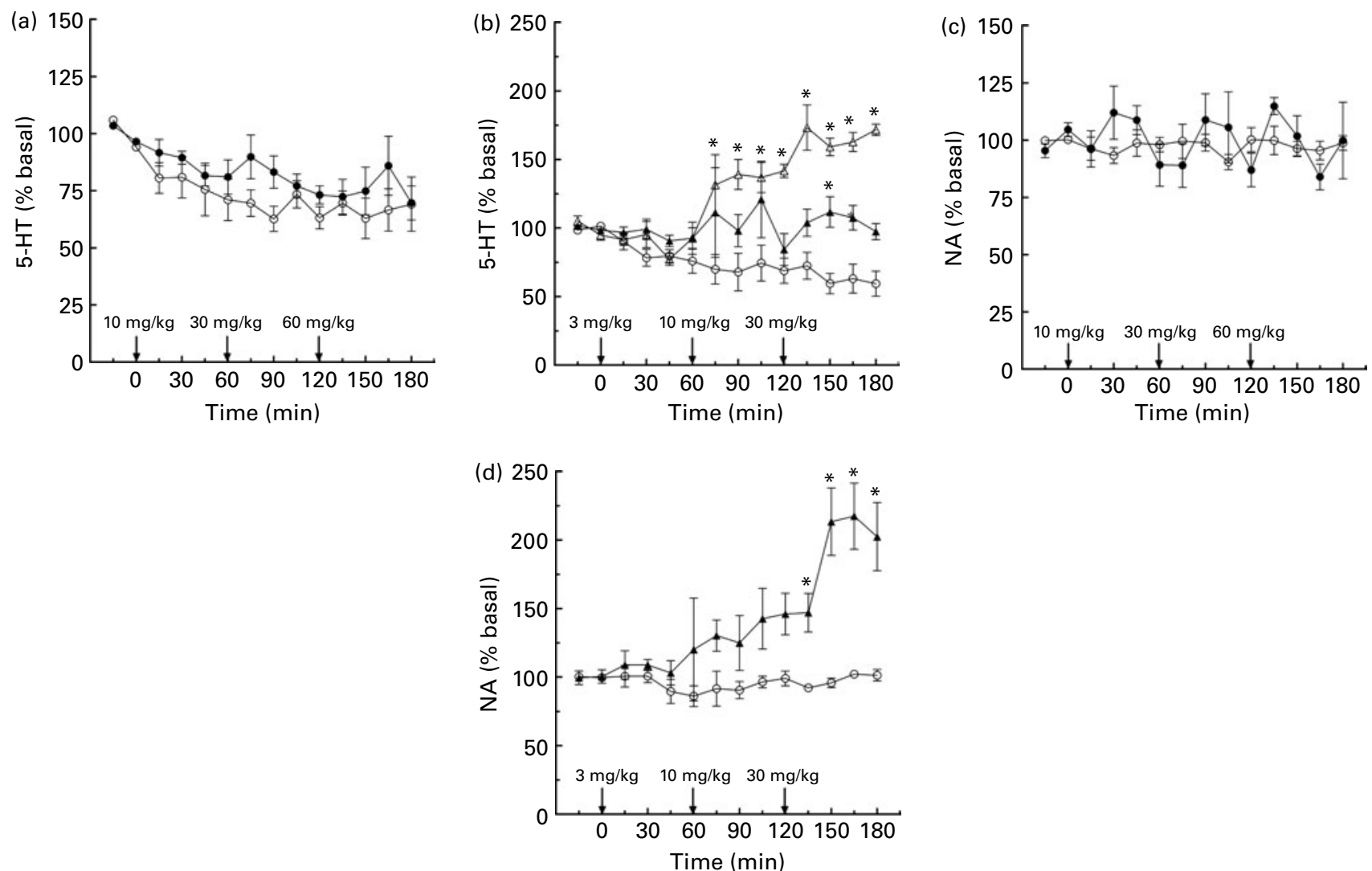

Fig. 5. In vivo microdialysis in the rat hippocampus. Rats were administered vehicle (VEH, $-0-)$, oregano extract (OREG, $-\bullet-; 10$, 30 and 60 mg/kg), fluoxetine (FLU, $-\Delta-; 3,10$ and $30 \mathrm{mg} / \mathrm{kg}$ ) or imipramine (IMI, $-\mathbf{\Delta -} ; 3,10$ and $30 \mathrm{mg} / \mathrm{kg})$, intraperitoneally, at 0,60 and $120 \mathrm{~min}$. Extracellular monoamine levels ((a and b) serotonin (5-hydroxytryptamine; 5-HT), (c and d) noradrenaline (NA)) are shown as means, with their standard errors represented by vertical bars ( $n$ 4-6), and are expressed as percentage basal values. Mean values were significantly different compared with the respective vehicle control group ( $P<0.05$; Bonferroni $p o s t$ hoc test). OREG induced an overall increase in the extracellular levels of 5-HT (a) while having no statistically significant effect on NA levels (c). Both FLU and IMI significantly increased 5-HT levels (b), while only IMI increased NA levels (d).

test $^{(43,44)}$, marble-burying test ${ }^{(45)}$ and light-dark box test ${ }^{(46,47)}$. Acute administration of oregano extract resulted in a dose-dependent reduction of immobility behaviour in the forced swim test, in agreement with effects of the reference compounds, IMI and VEN, both of which have dual serotonin/NA reuptake inhibitory activity and have been proven efficacious in this behavioural paradigm ${ }^{(48,49)}$. By analogy, the observed effect of oregano extract was therefore suggestive of mood-enhancing activity in human subjects. Furthermore, acute treatment with oregano extract resulted in anxiolytic-like effects in both the marble-burying and light-dark box tests. Oregano extract significantly reduced the number of marbles buried in the marble-burying test, in concordance with the effects of FLU (serotonin reuptake inhibitor) and VEN, both within the present study and as reported in the literature $^{(50-52)}$. Acute administration of oregano extract resulted in significant increases in the time spent in the light compartment of the light-dark box, which is suggested to be indicative of anxiolytic activity ${ }^{(53)}$. Our data are supported by a recent study describing the anxiolytic-like effect of CAR, the major constituent of oregano extract, in mice in the elevated plus-maze test ${ }^{(54)}$.
Subsequently, oregano extract was orally administered to mice in a sub-chronic dosing regimen before testing in the forced swim test. Immobility behaviour was reduced by all three doses tested, the lowest dose having the greatest effect. The fact that the lowest dose of oregano extract was the most active, and that significant effects were not observed above a dose of $150 \mathrm{mg} / \mathrm{kg}$, indicates that its behavioural activity lies within a particular dose range and may be saturable in vivo. Most importantly, oregano extract, following both acute, i.p. administration and sub-chronic, p.o. administration, demonstrated statistically significant effects in a widely used rodent model in which compounds with monoamine reuptake inhibitory activity, shown to elevate depressed mood in human subjects, have proven efficacy ${ }^{(43,44)}$. Moreover, the observed effects are in agreement with a recent study demonstrating a significant reduction in immobility behaviour in the forced swim test following administration of another commonly used plant, Rosmarinus officinalis. The reported effects were shown to be due to interactions with monoaminergic neurotransmission and were suggested to be dependent upon its interaction with several receptor subtypes $\left(5-\mathrm{HT}_{1 \mathrm{~A}}, 5-\mathrm{HT}_{2 \mathrm{~A}}, 5-\mathrm{HT}_{3}, \alpha_{1}, \mathrm{D}_{1} \text { and } \mathrm{D}_{2}\right)^{(55)}$. 

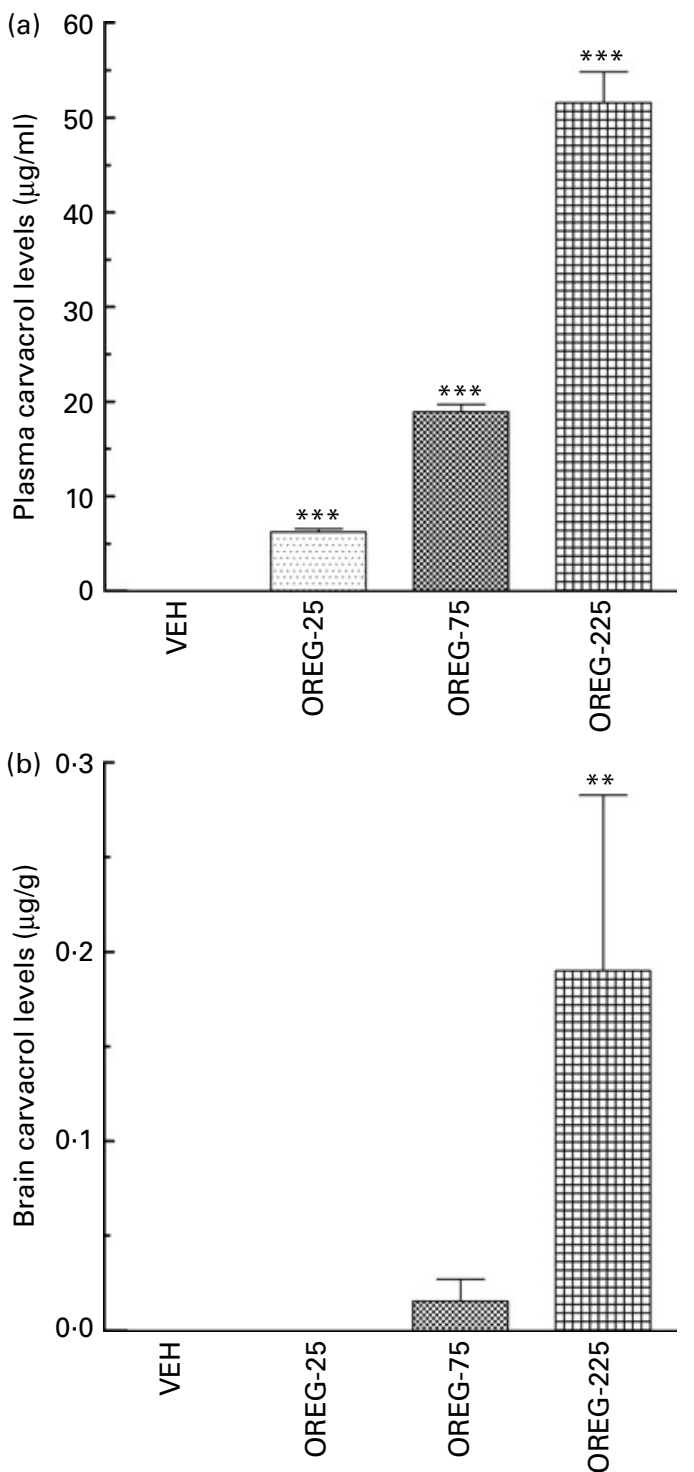

Fig. 6. Plasma and brain carvacrol levels. Mice were administered oregano extract (OREG; 25,75 or $225 \mathrm{mg} / \mathrm{kg}$ ) or vehicle (VEH; maize oil), per os, $24.5,18.5,5.5,3.5$ and $1.5 \mathrm{~h}$ before killing. (a) Plasma total carvacrol levels are shown as means, with their standard errors represented by vertical bars ( $n$ 10), and are expressed as $\mu \mathrm{g} / \mathrm{ml}$ plasma. Mean values were significantly different compared with the control group ( $\left.{ }^{\star \star \star} P<0.001\right)$. (b) Brain carvacrol levels are shown as means, with their standard errors represented by vertical bars, and are expressed as $\mu \mathrm{g} / \mathrm{g}$ brain tissue; OREG-25: carvacrol levels were below the limit of quantification $(<0.025 \mu \mathrm{g} / \mathrm{g})$; OREG-75: two out of ten mice had measurable carvacrol; OREG-225 ( $n$ 10). Mean values were significantly different compared with the control group $\left({ }^{* \star} P<0.01\right)$. Thus, plasma and brain carvacrol levels demonstrated clear dose dependency.

In order to investigate which of the constituents of oregano extract may be responsible for the observed inhibition of serotonin reuptake, an additional hSERT inhibition assay was performed. The addition of TQ or CAR to the $\mathrm{IC}_{50}$ concentration of oregano extract (containing $0.244 \mu \mathrm{M}-\mathrm{TQ}$ and $1.6 \mu \mathrm{M}-\mathrm{CAR}$ ) significantly increased the percentage inhibition of hSERT, suggesting that the presence of both compounds contributes to the biological activity profile of our oregano extract. In addition, dose-dependent plasma CAR levels were observed in mice administered multiple doses of oregano extract, and the two higher doses resulted in measurable levels of CAR within brain tissue, thus further indicating that an active component of oregano extract crosses the blood-brain barrier.

We have shown here, through cellular uptake inhibition assays, in vivo microdialysis and rodent behavioural tests, that oregano extract acts as a triple reuptake inhibitor in vitro, moderately increases brain extracellular serotonin levels and induces positive behavioural effects in animal models, which are associated with antidepressant- and anxiolytic-like activity when compounds with a similar profile are administered to human subjects. To the best of our knowledge, oregano extract is the first nutritional ingredient exhibiting all of the aforementioned properties. In addition, both the in vitro and in vivo data indicate that our oregano extract demonstrates moderate efficacy, in comparison with pharmaceutical antidepressant or anxiolytic compounds, as would be expected for a dietary constituent. We suggest that, in agreement with published studies on $M$. officinalis ${ }^{(11)}, S$. lavandulaefolia ${ }^{(12,13)}$ and $S$. officinalis ${ }^{(14)}$, where attention ${ }^{(11)}, \operatorname{mood}^{(12)}$ and memory $^{(12-14)}$ were improved with nutritional supplementation, oregano extract may comprise a viable strategy to maintain a healthy mood status and enhance mental well-being in humans and propose the initiation of appropriate investigations.

\section{Acknowledgements}

oréVida $^{\mathrm{TM}}$ is a trademark of DSM. With the exception of J. A. and J. M. E., all other authors are (or were at the time the studies were performed) employed by DSM. We gratefully acknowledge the technical expertise of Vincent Acker and Albine Bompard, both of whom made significant contributions to the performance of in vitro screening and profiling assays. We also acknowledge the constructive input of Kevin Prudence in discussions during the preparation of the manuscript. A. O. M., A. F., N. S., H. R., T. W., S. E., J. A. and J. M. E. contributed to the laboratorybased research described in the study. A. O. M., A. F., N. S., T. W., A. W., G. S., B. C., C. K., M. H. M. and R. G. were involved in discussions concerning initial experimental design and data interpretation. A. O. M., A. F., N. S. and T. W. performed data analyses. A. O. M., A. F., N. S., J. M. E. and M. H. M. contributed to writing the manuscript. The present study received no specific grant from any funding agency in the public, commercial or not-for-profit sectors. No conflicts of interest occurred in relation to the experiments described in the present study.

\section{References}

1. Food and Health Forum (2008) The links between diet and behaviour: the influence of nutrition on mental health: Associate Parliamentary Food and Health Forum. http://www.fhf.org.uk/ 
2. Cornah D (2006) Feeding Minds: the Impact of Food on Mental Health. London: Mental Health Foundation. http:// www.mentalhealth.org.uk

3. Van de Weyer C (2005) Changing Diets, Changing Minds: How Food Affects Mental Well Being and Behaviour. London: Sustain.

4. Fernstrom JD (1990) Aromatic amino acids and monoamine synthesis in the central nervous system: influence of the diet. I Nutr Biochem 1, 508-517.

5. Wurtman RJ \& Fernstrom JD (1975) Control of brain monoamine synthesis by diet and plasma amino acids. Am J Clin Nutr 28, 638-647.

6. Frederick AL \& Stanwood GD (2009) Drugs, biogenic amine targets and the developing brain. Dev Neurosci 31, 7-22.

7. Jayanthi LD \& Ramamoorthy S (2005) Regulation of monoamine transporters: influence of psychostimulants and therapeutic antidepressants. AAPS J 7, E728-E738.

8. Lucki I (1998) The spectrum of behaviors influenced by serotonin. Biol Psychiatry 44, 151-162.

9. Missale C, Nash SR, Robinson SW, et al. (1998) Dopamine receptors: from structure to function. Physiol Rev 78, 189-225.

10. Haskell CF, Scholey AB, Jackson PA, et al. (2008) Cognitive and mood effects in healthy children during 12 weeks' supplementation with multi-vitamin/minerals. $\mathrm{Br} J \mathrm{Nutr}$ 100, 1086-1096.

11. Kennedy DO, Scholey AB, Tildesley NT, et al. (2002) Modulation of mood and cognitive performance following acute administration of Melissa officinalis (lemon balm). Pharmacol Biochem Behav 72, 953-964.

12. Tildesley NT, Kennedy DO, Perry EK, et al. (2005) Positive modulation of mood and cognitive performance following administration of acute doses of Salvia lavandulaefolia essential oil to healthy young volunteers. Physiol Behav 83, 699-709.

13. Tildesley NT, Kennedy DO, Perry EK, et al. (2003) Salvia lavandulaefolia (Spanish sage) enhances memory in healthy young volunteers. Pharmacol Biochem Behav 75, 669-674.

14. Scholey AB, Tildesley NT, Ballard CG, et al. (2008) An extract of Salvia (sage) with anticholinesterase properties improves memory and attention in healthy older volunteers. Psychopharmacology (Berlin) 198, 127-139.

15. Ofir R, Tamir S, Khatib S, et al. (2003) Inhibition of serotonin re-uptake by licorice constituents. JMol Neurosci 20, 135-140.

16. Yáñez M, Fraiz N, Cano E, et al. (2006) Inhibitory effects of cis- and trans-resveratrol on noradrenaline and 5-hydroxytryptamine uptake and on monoamine oxidase activity. Biochem Biophys Res Commun 344, 688-695.

17. Dhingra D \& Sharma A (2006) Antidepressant-like activity of Glycyrrhiza glabra L. in mouse models of immobility tests. Prog Neuropsychopharmacol Biol Psychiatry 30, 449-454.

18. Dhingra D, Parle M \& Kulkarni SK (2004) Memory enhancing activity of Glycyrrbiza glabra in mice. J Ethnopharmacol $\mathbf{9 1}$, $361-365$

19. de Moraes Pultrini A, Galindo LA \& Costa M (2006) Effects of the essential oil from Citrus aurantium L. in experimental anxiety models in mice. Life Sci 78, 1720-1725.

20. Bergström LS \& Lynöe N (2008) Enhancing concentration, mood and memory in healthy individuals: an empirical study of attitudes among general practitioners and the general population. Scand J Public Health 36, 532-537.

21. Fowler A, Seifert N, Acker V, et al. (2006) A nonradioactive high-throughput/high-content assay for measurement of the human serotonin reuptake transporter function in vitro. J Biomol Screen 11, 1027-1034.

22. Qian Y, Galli A, Ramamoorthy S, et al. (1997) Protein kinase C activation regulates human serotonin transporters in HEK-293 cells via altered cell surface expression. J Neurosci 17, 45-57.
23. Holt A, Sharman DF, Baker GB, et al. (1997) A continuous spectrophotometric assay for monoamine oxidase and related enzymes in tissue homogenates. Anal Biochem 244, 384-392.

24. White HL, Scates PW \& Cooper BR (1996) Extracts of Ginkgo biloba leaves inhibit monoamine oxidase. Life Sci $\mathbf{5 8}$, 1315-1321.

25. Yamada M \& Yasuhara H (2004) Clinical pharmacology of MAO inhibitors: safety and future. Neurotoxicology $\mathbf{2 5}$, 215-221.

26. Lucki I, Dalvi A \& Mayorga AJ (2001) Sensitivity to the effects of pharmacologically selective antidepressants in different strains of mice. Psychopharmacology (Berl) 155, 315-322.

27. Porsolt RD, Bertin A \& Jalfre M (1977) Behavioral despair in mice: a primary screening test for antidepressants. Arch Int Pharmacodyn Ther 229, 327-336.

28. Njung'e K \& Handley SL (1991) Evaluation of marble-burying behavior as a model of anxiety. Pharmacol Biochem Behav 38, 63-67.

29. Njung'e K \& Handley SL (1991) Effects of 5-HT uptake inhibitors, agonists and antagonists on the burying of harmless objects by mice; a putative test for anxiolytic agents. Br J Pharmacol 104, 105-112.

30. Londei T, Valentini AMV \& Leone VG (1998) Investigative burying by laboratory mice may involve non-functional, compulsive, behaviour. Behav Brain Res 94, 249-254.

31. Broekkamp CL, Rijk HW, Joly-Gelouin D, et al. (1986) Major tranquillizers can be distinguished from minor tranquillizers on the basis of effects on marble burying and swiminduced grooming in mice. Eur J Pharmacol 126, 223-229.

32. Crawley JN (1981) Neuropharmacologic specificity of a simple animal model for the behavioral actions of benzodiazepines. Pharmacol Biochem Behav 15, 695-699.

33. Kreiss DS, Wieland S \& Lucki I (1993) The presence of a serotonin uptake inhibitor alters pharmacological manipulations of serotonin release. Neuroscience 52, 295-301.

34. Malagié I, Trillat AC, Jacquot C, et al. (1995) Effects of acute fluoxetine on extracellular serotonin levels in the raphe: an in vivo microdialysis study. Eur J Pharmacol 286, 213-217.

35. Felton TM, Kang TB, Hjorth S, et al. (2003) Effects of selective serotonin and serotonin/noradrenaline reuptake inhibitors on extracellular serotonin in rat diencephalon and frontal cortex. Naunyn Schmiedebergs Arch Pharmacol 367, 297-305.

36. Maione S, Palazzo E, Pallotta M, et al. (1997) Effects of imipramine on raphe nuclei and prefrontal cortex extracellular serotonin levels in the rat. Psychopharmacology (Berl) 134, 401-405.

37. Rutter JJ \& Auerbach SB (1993) Acute uptake inhibition increases extracellular serotonin in the rat forebrain. $J$ Pharmacol Exp Ther 265, 1319-1324.

38. Paxinos G \& Watson C (1986) The Rat Brain in Stereotaxic Coordinates. London: Academic Press.

39. Carlier PR, Lo MM, Lo PC, et al. (1998) Synthesis of a potent wide-spectrum serotonin-, norepinephrine-, dopaminereuptake inhibitor (SNDRI) and a species-selective dopamine-reuptake inhibitor based on the gamma-amino alcohol functional group. Bioorg Med Chem Lett 8, 487-492.

40. Skolnick P, Popik P, Janowsky A, et al. (2003) Antidepressant-like actions of DOV 21,947: a "triple" reuptake inhibitor. Eur J Pharmacol 461, 99-104.

41. Skolnick P, Popik P, Janowsky A, et al. (2003) "Broad spectrum" antidepressants: is more better for the treatment of depression? Life Sci 73, 3175-3179.

42. Nutt DJ (2008) Relationship of neurotransmitters to the symptoms of major depressive disorder. J Clin Psychiatry 69, Suppl. E1, 4-7. 
43. Cryan JF, Valentino RJ \& Lucki I (2005) Assessing substrates underlying the behavioral effects of antidepressants using the modified rat forced swimming test. Neurosci Biobehav Rev 29, 547-569.

44. Sillaber I, Panhuysen M, Henniger MS, et al. (2008) Profiling of behavioral changes and hippocampal gene expression in mice chronically treated with the SSRI paroxetine. Psychopharmacology (Berl) 200, 557-572.

45. Hirano K, Kimura R, Sugimoto Y, et al. (2005) Relationship between brain serotonin transporter binding, plasma concentration and behavioural effect of selective serotonin reuptake inhibitors. $\mathrm{Br} J$ Pharmacol 144, 695-702.

46. Hascoët M, Bourin M \& Nic Dhonnchadha BA (2000) The influence of buspirone, and its metabolite 1-PP, on the activity of paroxetine in the mouse light/dark paradigm and four plates test. Pharmacol Biochem Behav 67 , 45-53.

47. Bourin M, Redrobe JP, Hascoët M, et al. (1996) A schematic representation of the psychopharmacological profile of antidepressants. Prog Neuropsychopharmacol Biol Psychiatry 20, 1389-1402.

48. Mason SS, Baker KB, Davis KW, et al. (2009) Differential sensitivity to SSRI and tricyclic antidepressants in juvenile and adult mice of three strains. Eur J Pharmacol 602, $306-315$.
49. Kulkarni SK \& Dhir A (2007) Effect of various classes of antidepressants in behavioral paradigms of despair. Prog Neuropsychopharmacol Biol Psychiatry 31, 1248-1254.

50. Nicolas LB, Kolb Y \& Prinssen EP (2006) A combined marble burying-locomotor activity test in mice: a practical screening test with sensitivity to different classes of anxiolytics and antidepressants. Eur J Pharmacol 547, 106-115.

51. Kobayashi T, Hayashi E, Shimamura M, et al. (2008) Neurochemical responses to antidepressants in the prefrontal cortex of mice and their efficacy in preclinical models of anxiety-like and depression-like behavior: a comparative and correlational study. Psychopharmacology (Berl) 197, $567-580$.

52. Li X, Morrow D \& Witkin JM (2006) Decreases in nestlet shredding of mice by serotonin uptake inhibitors: comparison with marble burying. Life Sci 78, 1933-1939.

53. Bourin M \& Hascoët M (2003) The mouse light/dark box test. Eur J Pharmacol 463, 55-65.

54. Melo FHC, Venâncio ET, de Sousa DP, et al. (2010) Anxiolytic-like effect of carvacrol (5-isopropyl-2-methylphenol) in mice: involvement with GABAergic transmission. Fundam Clin Pharmacol 24, 437-443.

55. Machado DG, Bettio LE, Cunha MP, et al. (2009) Antidepressant-like effect of the extract of Rosmarinus officinalis in mice: involvement of the monoaminergic system. Prog Neuropsychopharmacol Biol Psychiatry 33, 642-650. 